\title{
CREATIVE SYNERGY AS A POTENTIAL FACTOR FOR THE DEVELOPMENT OF SOCIAL INNOVATIONS
}

\author{
Rasa Pakeltienė, Aistė Ragauskaitė \\ Aleksandras Stulginskis University, Lithuania \\ rasa.pakeltiene@asu.lt; aiste.ragauskaite@asu.lt
}

\begin{abstract}
In today's context of social sciences and practical discussions teamwork, synergy and synergy effects are considered to be one of the most important research objects. Creativity leads any organizational structure to successful solution of a problem and promotes the achievement of not individual but synergy goals, which are the result of generated and practically applied social innovations. The potential of teamwork synergy is transmitted through team dynamics, team creative process, as well as team purpose. The aim of this research is to identify the indicators describing the potential of synergy regarding team creative process and to evaluate their importance in the team creative process while developing innovative solutions. A case analysis method is applied: two different teams, which performed creative tasks, were chosen and analysed. In order to estimate the potential of synergy of creativity, a set of quantitative and qualitative indicators was formed. Features describing each indicator were evaluated by using questionnaires filled by the teams participating in the research. In addition, the teams were observed, in order to estimate the team creative process. The results of the research are valuable for authorities of organizations, who aim at greater synergy results and social innovations encouraging the development of public, social and business interests and creating multiplying effects of ideas. The generalized findings of the research are presented in the article, as well as the applied methods of scientific literature analysis and synthesis, abstraction.
\end{abstract}

Key words: creative synergy, group dynamics, teamwork, social innovations.

\section{Introduction}

Society influenced by the globalization processes faces many challenges, which insist on integrated, complex as well as collective decisions. Scientists and practitioners agree that while making collective decisions, interested parties share their knowledge and experience, adopt specific roles and become involved in the process of creativity - in this way synergy of knowledge complementarity occurs.

Authors Kelley (2001), Paulus \& Nijstad (2003), Sawyer (2007), Tu (2009) et al., agree that teams allow multiple perspectives, skills, and expertise to come together and meld brainpower to achieve more successful performance. Consequently, teams are a primary source of creativity and innovation in any organization. Climer (2016) summarised Katzenbach $\&$ Smith (1999) research results and found out the new definition of word team and present it a rather aspirational one, 'a team is a small number of people with complementary skills who are committed to a common purpose, performance goals, and approach for which they hold themselves mutually accountable' (Climer, 2016). It is necessary to discuss about team, which makes collective and innovative decisions, because in modern organizations employees are empowered to work independently and leadership style shifted from so popular democratic or liberal leadership to transformational. In this way, a field for the development of new, panoramic thinking, extraordinary insights and social innovations is created. Authors of this article agree with Bissola \& Imperatori (2011) statements that creative teams are not the 'simple sum of individual creative skills'.
Rather, teams have incredible creative potential if the group dynamics and team processes are high functioning (Bissola \& Imperatori, 2011; Hülsheger, Anderson, \& Salgado, 2009).

Previous scientific researches and insights have served to highlight the fact that in the context of modern knowledge society it is not sufficient to analyze the experience of teams related to collective decisions while using ordinary methods and approaches. Collective actions help to achieve synergetic results only in that case when the team has clearly defined objective (team purpose), creative actions start at the beginning of team formation process (team creative process) and the team is dynamic (team dynamics), open and able to adapt to changing environment.

Aim of the research - creative synergy as a potential factor for social innovations.

This research aims to identify the indicators that are describing potential of synergy regarding team creative process and to evaluate their importance in the team creative process while developing innovative solutions.

Research objectives are as follows: to analyse theoretical conceptualization of creative synergy and social innovations; to identify the indicators describing the potential of creative synergy; to evaluate the expression of potential creative synergy in the team creative process while developing innovative solutions.

Research methods: the analysis and synthesis of scientific literature, induction and deduction, observation of team working, questionnaire and logical abstraction methods. 
Creativity involves an ability to come up with new and different viewpoints on a subject. It involves breaking down and restructuring our knowledge about the subject in order to gain new insights into its nature. However, any definition of creativity is complicated because the concept has many dimensions (Creativity and..., 2017). Climer (2016) analysed various types of studies related to creativity. Author concluded that definition of creativity has involved four 'P', e.g. creative process, creative product, creative person and creative environment (sometimes referred to as 'press', in order to maintain four ' $\mathrm{P}$ ' words). Plucker et al., (2004) attempted to incorporate the four ' $\mathrm{P}$ ' within the definition: 'Creativity is the interaction among aptitude, process, and environment by which an individual or group produces a perceptible product that is both novel and useful defined with a social context'. More simply creativity can be defined as novelty that is useful.

Creativity and innovations in scientific literature are analyzed as inseparable and complementary phenomena; thus, in this case, innovations cannot be defined by traditional definition considering an innovation only as a novelty. Panoramic view has to be adopted and it is necessary to admit that innovation creates synergetic effects only when new product, service or process and etc., makes social changes of a lasting nature in the multilayered process of new idea transformation. Csikszentmihalyi (1996) explained this complexity within the systems theory. He states, 'Creativity does not happen inside people's heads, but in the interaction between person's thoughts and a sociocultural context. It is a systemic rather than an individual phenomenon'. Sawyer (2007) explores the power of creativity in teams and the factors that foster and diminish creativity in groups. When the variables that foster creativity exist in a team at just the right level, the team achieves creative synergy. Creative synergy is defined as the interactions among team members where the collective creative results are greater than the sum of their individual efforts. Climer (2016) through an extensive literature review has concluded that three components are needed for creative synergy with a team: team dynamics, creative team process, and team purpose.
Also, team couching is an important technique applied to motivate and encourage team to focus on final work. During teamwork the following techniques could be applied: assessment of teamwork, identification of team mission, improvement of principles of teamwork, estimation of input and expectations of team members. In addition, a technique of force field analysis, session of feedback, promotion of emotional intelligence, method of questions can be applied in teamwork for the improvement of team effectiveness (Misiukonis, Matusevičiūte, \& Grajauskas, 2015). After taking into consideration the principles of teamwork, it can be stated that team work is favorable activity for creativity and innovations. Sources, knowledge and qualification can be concentrated in team and this influences the team success significantly. A person, who cooperates with a group, tends to solve situations while using creativity (Hardagon \& Bechy 2006).

Despite the fact that creativity is very promoted, creative thinking of team is not analyzed very widely in scientific literature. There are many individual techniques promoting creativity; however, group techniques can be distinguished as well. Buzys (2016) states that he has found 99 techniques for creativity development - these techniques can be applied in team activities as well. The following techniques can be used: six thinking hats, SCAMMPER (substitute, combine, adapt, magnify, modify, put, eliminate, rearrange, and reverse), NAF (novelty, attractiveness, and fulfillment), visual stimulation, a tree of problems, a source of wealth, life river, geologists of ideas, and etc. However, it is necessary to reconsider the fact that each technique should be applied while observing feelings and behavior of the group.

Team dynamics. Devitt, Philip, \& McLachlan (2010) team dynamics defined as team ability adapt to each other's opinions, working methods and microclimate. According to Anderson (2005), the determinants that describe team dynamics are the following: team cohesiveness, team independence, team heterogeneity, team opportunistic practices, and team hypothesis-driven thinking. Team variables have a unique relationship with student affect and simulation performance.

\begin{tabular}{|c|c|c|}
\hline I N P U T & PROCES S & O U T P U T \\
\hline $\begin{array}{l}\text { Personality characteristics, } \\
\text { knowledge level of group } \\
\text { members }\end{array}$ & $\begin{array}{l}\text { Group interactions, communication, } \\
\text { the level of social capital (trust, } \\
\text { safety, norms and rules, etc.) }\end{array}$ & $\begin{array}{l}\text { Performance outcomes, } \\
\text { Expressed results, } \\
\text { Creative synergy }\end{array}$ \\
\hline
\end{tabular}

Source: developed by Hackman, 1987; Climer, 2016.

Figure 1. Input, process, and output categories. 
Authors of this article would like to add to previously mentioned determinants describing team dynamics confidence among team members, respect to each other's work methods and skills, satisfaction in teamwork when members feel free to reveal themselves and express their thoughts. Creative synergy and team dynamics occur only in area of open communication when team members are free to share their knowledge, positive and negative experiences and when teamwork unites the differences of team members and transform them to advantages.

Input variables are factors that are determined before a group gets together. This may include personality characteristics, past experience, and diversity of the team. Process variables, on the other hand, include variables that occur once the group begins interacting, such as communication, trust among the group, team climate, and sense of safety within the team (Hülsheger et al., 2009). It is worth to mention that planned team results or creative synergy occurs when an innovation, which addresses social challenges in the long term, takes place. Team members help to make a change, which is not individual or team's change, but societal.

Panoramic view has to be adopted and it is necessary to admit that innovation creates synergetic effects only when new product, service or process and etc., makes social changes of a lasting nature in the multilayered process of new idea transformation.

Team creative process. In the scientific literature (Lubart, 2001; Basadur, Gelade, \& Basadur, 2014), numerous creative processes developed over the years have been analyzed, but most follow some variation of problem-finding, problem-solving or decision-finding, and decision-implementation. While analyzing the process of making decisions, it is possible to identify interferences in communication, knowledge and experience, which lead to the lack of team synergy and social innovations. Authors of this research believe that the process of team creativity has to be analyzed while revealing the potential of creative synergy, which is described by the following factors: format of team forming, time of teamwork and time for decision-making, capacity of team's strategical thinking, methods of decision-making awareness, depth and width of analyzed situations/made decisions, anticipation of alternatives of decisions/ ideas and implementational steps.

Team purpose. Understanding the purpose of team actions and the expected outcomes - is a critical component for teams to achieve creative synergy. While a team may be assigned a specific purpose, team members work together to further develop and identify with that purpose; therefore, it is a critical internal-process variable for a team's creative synergy (Climer, 2016). Team purpose is always challenging and exceeds the normal team capacity. Creative synergy will be achieved only in that case when the team will be able to think outside the box and generate such social innovations, which create not individual benefits and effects of multiplication. After analysis of determinants that are describing creative synergy, it is worth to develop understanding of the role of social innovations as an outcome of creative synergy.

Social innovations traditionally are defined as generation and implementation of new ideas while aiming to formulate effective networks of relations among people and social interactions and which are directed to the implementation of mutual objectives (Marcy et al., 2007; Mumford, 2002). According to Phill et al., (2008), social innovations are not only products, processes or technology - they also can be principles, ideas, and a part of legislation, social movement, intervention or other kind of facility. However, as Moulaert et al., (2013) emphasize, social innovations are more related to the process creating innovative social networks among individuals and their groups than to specific products or achievements (Moulaert et al., 2013). Social innovations are new decisions (products, services, models, markets, processes, and etc.) corresponding to social need (more effective decision than the existing one), new possibilities, relations or better use of resources. Social innovations are oriented towards the enhancement of societal capacity to operate (Caulier-Grice, 2012). Social innovations are the development of new ideas (products, services, models) aiming at the satisfaction of social needs. Scientists have described three dimensions, which are satisfied by social innovations: the satisfaction of human needs (content dimension); changes in social relation especially with regard to governance (process dimension); an increase in socio-political capability and access to resources (empowerment dimension) (Gerometta, Hausermann, \& Longo, 2005).

Impact of social innovations can be related to the development of new institutions or new social frameworks. It can be admitted that social innovations do not solve social problems, but create social changes. They appear as new ideas or alternatives while applying new social practices in specific social groups. Santana (2014) and Daniel (2010) state that social innovations develop collective well-being. According to Santana (2014), social innovations are new social practices formed from collectives, specifically orientated towards achievement of the certain goal related to social changes or social networks that are necessary to be developed. The main distinctive properties of social innovations are orientation to novelty and targeted actions oriented towards desirable result. Social innovations are related to the actions of planned, coordinated, goal oriented 


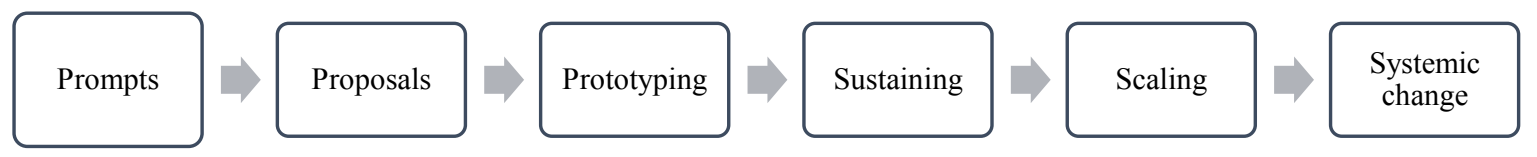

Source: developed by Caulier - Grice (2012).

Figure 2. Classical model of the process of social innovations.

and legal activities and which are performed by social agents and aim at social changes encouraging the development of new social practices in the future (Howaldt, 2010).

However, the most popular model described in scientific sources of social innovations is composed of six stages (Caulier - Grice et al., 2012): I stage. Needs or problems are highlighted. It is a primary stage, which is one of the most important, because the success of the party initiating the whole process may depend on the relevance of the problem. II stage. Proposals for satisfying needs - ideas are developed. Several alternatives are necessary - they have to be assessed respectively. It is not only a level of ideas this level relates to financial indicators, which have to be identified for the implementation of the idea. III stage. Prototyping. Testing idea in practice. Firstly, on the inovation level testing phase is activated in the most cases or the inovation itself is introduced in the stage of prototyping. Thus, there is a high number of innovative decisions that failed. Testing is a risk mitigation factor, which can determine wheter the decision is good or not. IV stage. A specific model is developed. Social innovation is oriented towards process; thus, in the most cases it is possible that a certain new structure, measure, method or other results can occur. Consequently, it can become a business model which is implemented by the society following principles of social innovations. $V$ stage. Development of social innovations. Success of social innovation also depends on level of its dissemination and on what extent the society is reached. Innovation is considered to be successful when it is disseminated widely. VI stage. Systemic changes. Due to the fact that the public sector is a common initiator of social innovations, social innovation leads to the implementation of systemic changes, which empowers the society to act and exist in the market.

In addition, elements of social innovations have to be highlighted together with the model: Ilevel: novelty, effectiveness, society empowerment to operate from idea to its implementation, social needs. II level: openness and cooperation, development of skills and attitude, new relations, cross-sectoral cooperation, usage of funds and resources in more efficient way. In the whole process of social innovations, team or group work is relevant. Parties can pass all stages of the development of social innovations only while cooperating in creative process.
Creative process of the decision making and implementation is also very important in developing social innovations, because it helps to reach the team purpose step by step, follow the stages of the creation of social innovations and apply creative, synergistic methods.

\section{Materials and Methods}

In order to estimate teamwork while developing social innovations in synergic conditions, a questionnaire was composed from three groups of questions. In the first group statements defining the team purpose were distinguished; the second group of questions estimates team dynamic and changes occurring in teamwork; the third group of questions was used to estimate teamwork. Two stages are important for the research. In order to identify properly the principles of teamwork, it is necessary to make observations during teamwork. The research of this article is composed of two research methods.

Firstly, two researchers perform observation while following observation protocol. Each team is estimated objectively. Received data has to be compared and it has to be complemented with researchers' observations and questionnaires filled by the teams. Kardelis (2016) states that while applying qualitative and quantitative methods in researches, analyzed phenomena can be estimated more sufficiently. According to Žydžiūnaitė (2017), an important role is played by the researcher in certain researches - he or she can identify additional information relevant to research.

Representatives of youth organizations and members of university community participated in the research. There were in total 10 teams analyzed; every team was composed of 5 members. In order to estimate statements, Likert scale was applied: 1 point - I totally disagree, 2 points - I disagree, 3 points - I neither agree nor disagree, 4 points - I tend to agree, 5 points - I agree, 6 points - I totally agree.

Two researchers observed how teams performed each task. To sum up, it can be stated that 8 teams out of ten formulated goals and clear results, 7 teams out of ten operated dynamically, made decisions effectively, organized work, team members motivated and supported emotionally each other as well as encouraged each other to take actions. Team leaders, idea developers, observers, work organizers and goal oriented individuals were developed in teams. In 9 teams out of ten, teamwork depended on emotional 
level and members, who have strong characters. In most cases, the team leader, who possessed leadership qualities, set the work atmosphere.

\section{Results and Discussion}

Creative synergy is achieved in that case when team members are united by the common goal. The first group of questionnaire was aimed to estimate the strength of goal and to coordinate achievement of goal and development of social innovations.

Respondents agreed that a team is united by the common goal (5.6 points). However, they also stated that the team tries not only to achieve formulated goal but also best possible results (5.6). In the theoretical part relevance of teamwork while developing social innovations was highlighted; during the research, respondents also agreed that only a strong team is able to develop social innovations (5.4). Representatives of youth organizations and members of university community participated in the research - they were acquainted with social innovations on theoretical level; consequently, while estimating competences of team, respondents stated that the team should be qualified while developing social innovations (5.0). Also, the attention has to be paid to the fact that social innovations are oriented towards solution of social problems and respondents tend to agree with this statement (4.2). Creative synergy of team develops social innovations and acts in certain stages. Social innovations have to complete 6 stages from idea to its implementation; however, the respondents stated that stages of the social innovation development are more unclear than clear (3.6). Other estimated statements are connected to each other - they were introduced only to check the strength of respondent's opinion and are not discussed in details.

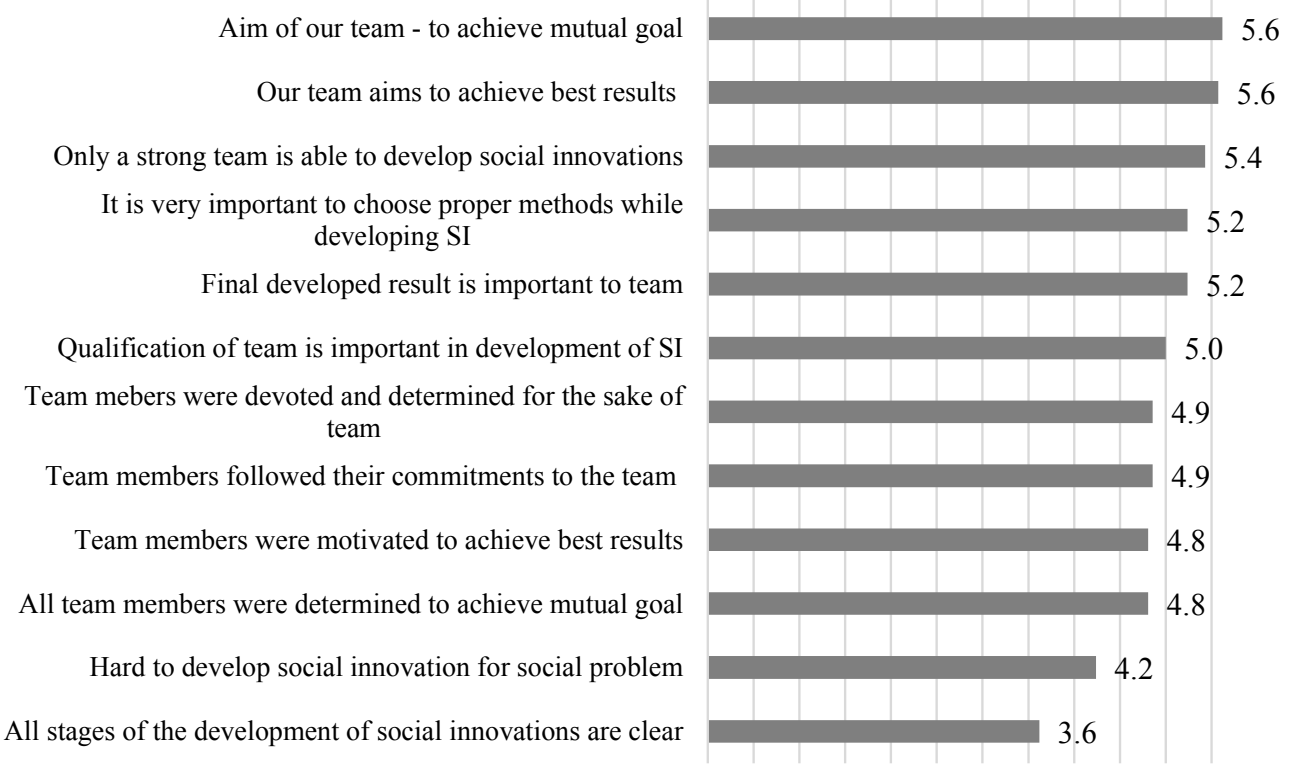

0.00 .51 .01 .52 .02 .53 .03 .54 .04 .55 .05 .5 Value

Figure 3. Estimation of Team Goal Achievement.

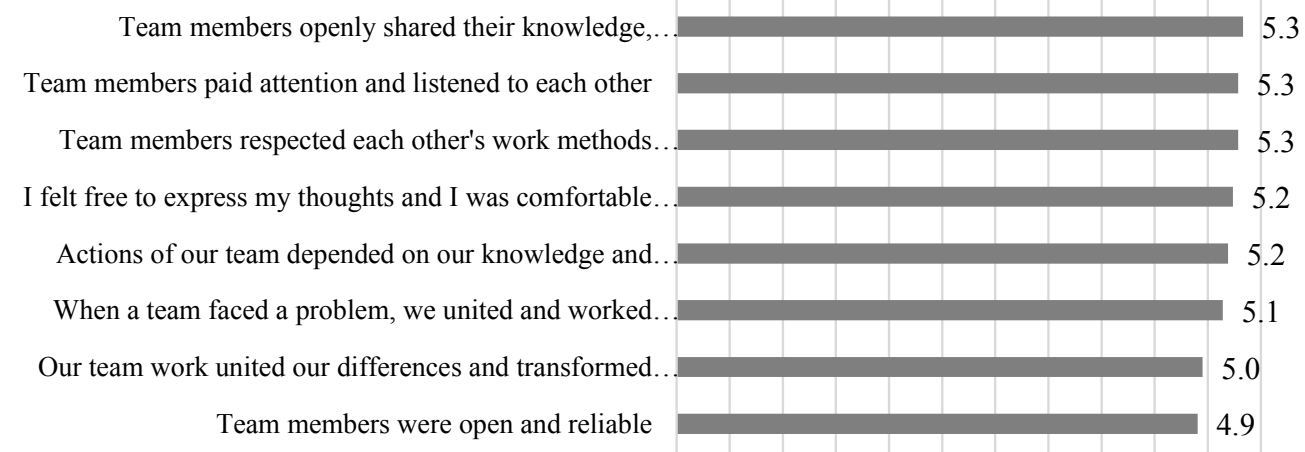

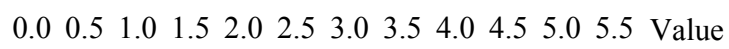

Figure 4. Team Dynamics. 
Principles of operation are important in creative process for each team. Synergy in this case is necessary when the team is trying to achieve mutual goal; thus, dynamic and principles of operation have to be harmonized. Every team can estimate its dynamic while analyzing achieved results.

Team dynamics in this group of questions was estimated while taking into account more human factor. Formation of member's role and emotional level are very important factors in team. Members of teams participating in research shared their knowledge, experience and information freely (5.3). Also, it can be observed that team members developed relations to each other and tried to listen to each other (5.3). According to received results, emotional state of teams was stable, because participants were able to reveal themselves and participate in all processes (5.2). While estimating synergy of team members and knowledge, it became obvious that team operation while performing tasks deepened on acquired knowledge and experience (5.2). Similarly to earlier group of questions, it became clear that the team had mutual goal and tried to achieve it; team members solved problems together and tried to work with them (5.1). Teamwork enabled teams to identify their differences and transform them into advantages (5.0). To conclude, it can be stated that the most important role in team dynamics is played by the human factor and team success depends on it.

Teamwork follows specific principles and each team operating in synergic way and developing social innovations reveals through these principles. Harmonized actions are a challenge to each team and there are cases when teams become demotivated; thus, it is very hard for them to achieve positive results. Researchers observed the results of demotivated team (i.e. few attempts to achieve goal which failed, demotivation of one person, and introduction of destruction in team by one person). After interviewing the respondents, it can be observed that teams fixated their ideas visually and in written (5.0). In order to achieve better results, teams tended to perform a
Ideas of our team is visual and written

After we made a new decision, we always discussed it and estimated its possible effectiveness, real...

Formation of our team encouraged creative thinking

Our team always discussed possible alternatives before making a decision

Our team searched for strategical decisions how to cope with obstacles and achieve best results

Our team used innovative methods for the development of ideas

Every team task (challenge) we estimated from different perspectives

Every team task we accepted as clearly defined and understood challenge

Team members always discussed advantages and disadvantages of possible solution

Every decision of our team is based on possible practical stages for its implementation

It took more time for our team to develop new ideas

We always discussed our aimed result, vision before performing team tasks

Our team analyzed all reasons that created situation before peforming a task

Our team had criteria and followed them while estimating possible solution

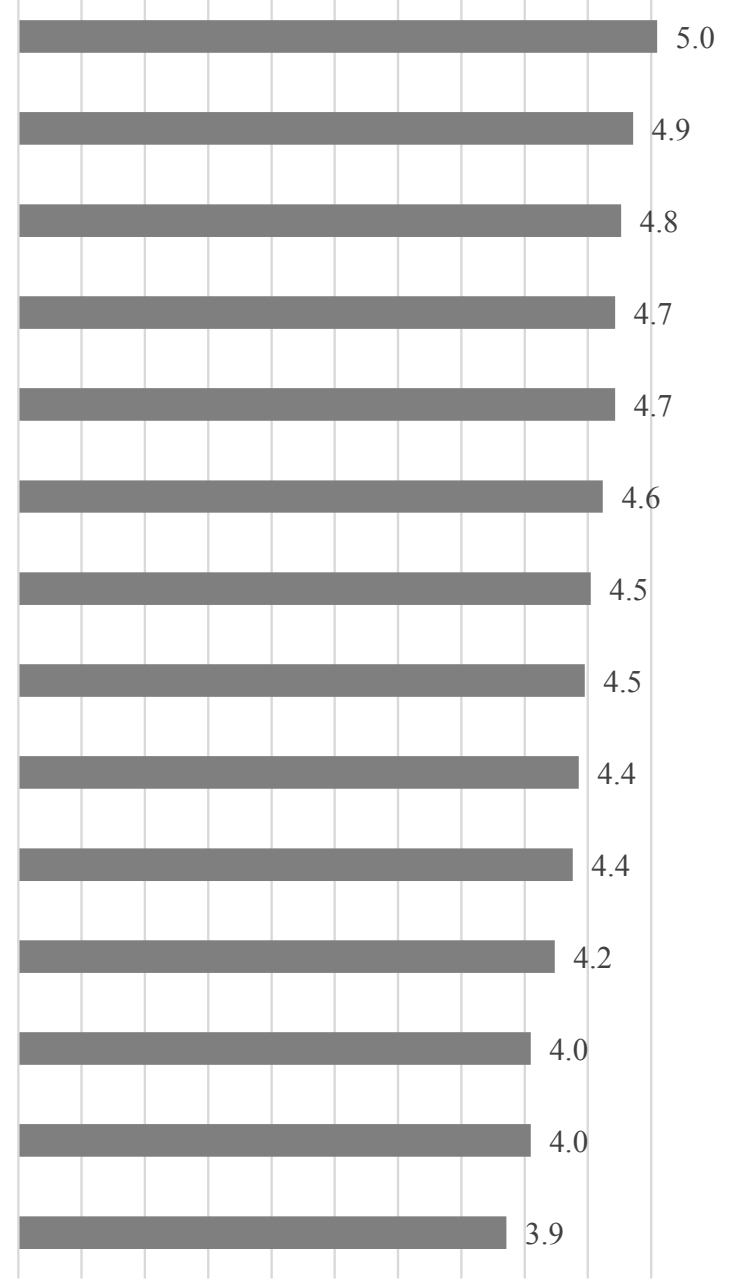

$\begin{array}{lllllllllll}0.0 & 0.5 & 1.0 & 1.5 & 2.0 & 2.5 & 3.0 & 3.5 & 4.0 & 4.5 & 5.0 \text { Value }\end{array}$

Figure 5. Team activities. 
deeper analysis and estimation of decision-making (4.9). Various creative methods were used for formation of teams; the research has shown that these methods encouraged teams to act creatively (4.8).

This group of questions is connected with former groups of questions and teams distinguish team's orientation towards goal while solving various problems (4.7). The formed teams estimated presented tasks creatively, innovatively, and accepted each task as a challenge. While interpreting research results, it can be stated that these teams worked on high level of motivation in order to achieve their goal. According to estimated statements, it can be concluded that teams acted intentionally, made grounded and motivated decisions (4.4). Teams estimated possible solutions according to their developed criteria (3.9); thus, it can be stated that they spent more time on development of new idea (4.2). The performed research has shown that formed groups of respondents were enough oriented towards systemic and purposeful work, accepted presented tasks and acted in concentrated manner.

\section{Conclusions}

Creative synergy as a potential factor for social innovations should be understood as a phenomenon which is new and open for scientific studies. More and more scientists and practitioners are discussing teamwork dynamics, common/collective goals and its created social value, social innovations. According to this idea, social innovations can be analyzed as an outcome or creative process and synergy among team members, their knowledge complementarity, shared roles and responsibility.

Indicators that are describing the potential of creative synergy are formulated according to the key elements of creative synergy and it is: team purpose, team creative process and team dynamics. Each of these elements has a various types of characteristics that merge and complement each other, thus the synergy is created.

The analysis of empirical studies has carried out that well identified team purpose and team dynamics is the most important potential of creative synergy. The common goal of the team and well selected methods, common vision and actions philosophy is leading team to synergy effects and the satisfaction of team results. The analysis of team dynamics has showed that the social innovations can be identified and implemented, if only the team is open minded, flexible and tolerant for other opinions, knowledge and experience.

\section{References}

1. Anderson, J.R. (2005). The Relationship Between Student Perceptions of Team Dynamics and Simulation Game Outcomes: An Individual-Level Analysis, Journal of Education for Business, 81:2, 85 - 90, DOI: 10.3200/JOEB.81.2.85-90.

2. Bissola, R., \& Imperatorini, B. (2011). Organizing individual and collective creativity: Flying in the face of creativity cliches. Creativity and Innovation management, 20(2).

3. Bsadur, M., Gelade, G., \& Basadur, T. (2014). Creative problem-solving process styles, cognitive work demands, and organizational adaptability. The journal of applied behavioral science, 50(1).

4. Buzys, A. (2016). Kürybiškas mastymas. 99 pratimai ir technikos norintiems mąstyti bei veikti kūrybiškai. (Creative thinking. 99 exercises and techniques for creative thinking). (in Lithuanian).

5. Caulier-Grice, J., Davies, A., Patrick, R., \& Norman, W. (2012). Defining Social Innovation. A deliverable of the project: 'The theoretical, empirical and policy foundations for building social innovation in Europe' (TEPSIE), European Commission - 7th Framework Programme, Brussels: European Commission, DG Research.

6. Creativity and its importance in business, (2017). Retrieved March 22, 2017, from: http://cw.routledge. com/textbooks/0415345421/about/pdf/sample.pdf.

7. Csikszentmihalyi, M. (1996). Creativity: Flow and the psychology of discovery and invention. NY: Harper Colins.

8. Devitt, B.J., Philip, J., \& McLachlan, S. (2010). Team Dynamics, Decision Making, and Attitudes Toward Multidisciplinary Cancer Meetings: Health Professionals' Perspectives. Journal or Oncology Practice. DOI: 10.1200/JOP.2010.000023.

9. Gerometta, J., Haussermann, H., \& Longo, J. (2005). Social innovation and civil society in urban governance: strategies for an inclusive city, Urban Studies.

10. Hackman, J.R. (1987). The Design of Work Teams. Handbook of Organizational Behavior.

11. Hardagon, A., \& Bechky, B. (2006). When collections of creatives become creative collectives: a field study of problem solving at work, Organization Science 17(4).

12. Kardelis, K. (2016). Moksliniu tyrimu metodologija ir metodai. Mokslo ir enciklopedijų leidybos centras (Scientific research methodology and methods. Science and Encyclopedia Publishing Center), Vilnius. (in Lithuanian). 
13. Kelly, T. (2001). The art of innovation: lessons in creativity from IDEO, Americas leading design firm. New York, NY: Double day.

14. Klimer, C. (2016). The development of creative synergy scale. Doctor dissertation. Antioch University.

15. Katzenbach, J., \& Smith, D. (1999). The wisdom of teams: creating the high-performance organization. New York, NY: HarperBusiness.

16. Lubart, T.I. (2001). Models of the creative process; Past, present and future. Creativity Research Journal, 13(3).

17. Marcy, R.T., \& Mumford, M.D. (2007). Social innovation: Enhancing creative performance through causal analysis. Creativity Research Journal, 19.

18. Matei, A., \& Antonie, C. (2015). Complexity Theory and the Development of the Social Innovation Procedia - Social and Behavioral Sciences 185.

19. Misiukonis, T., Matusevičiūtè, V., \& Grajauskas, M. (2015). Démesio, grupè! Praktiniai darbo su grupe büdai ir technikos (Attention, group! Practical methods and techniques for group work), Vilnius, Vaga. (in Lithuanian).

20. Murray, R., Caulier-Grice, J., \& Mulgan, G. (2010). The open book of social innovation. Great Britain: National Endowment for Science, Technology and the Art.

21. Moulaert, F., MacCallum, D., Mehmood, A., \& Hamdocuch, A. (2013). The international handbook of social innovation. Cheltenham: Edgar Elgar.

22. Mulgan, G., Tucker, S., Ali, R., \& Sanders, B. (2007). Social innovation what it is, why it matters and how it can be accelerated.

23. Mumford, M.D. (2002). Social innovation: ten cases from Benjamin Franklin, Creativity Research Journal, 14.

24. Paulus, P.B., \& Nijstad, B.A. (2003). Group creativity: innovation throgh collaboration. New York, NY: Oxfort University Press.

25. Phills, J.A., Deiglmeier, K., \& Miller, D.T. (2008). Rediscovering Social Innovation, Stanford Social Innovation Review, 6.

26. Plucker, J., Beghetto, R.A., \& Dow, G.T. (2004). Why isn't creativity more important to educational psychologist? Potential, pitfalls, and future direction in creativity research. Educational Psychologist, (39).

27. Santana, G.C. (2014). Social innovation: Moving the field forward. A conceptual framework Technological Forecasting \& Social Change 82.

28. Sawyer, R.K. (2001). Explaining creativity: the science of human innovation (2nd ed.). New York, NY: Oxford University Press.

29. Tu, C. (2009). Multilevel investigation of factors influencing creativity in NPD teams. Industrial Marketing Management, 38(1), 119 - 126. DOI: 10.1016/j.indmarman.2007.10.001.

30. Žydžiūnaite, V., \& Sabaliauskas, S. (2017). Kokybiniai tyrimai principai ir metodai (Qualitative research principles and methods, Vilnius, Vaga, (in Lithuanian). 